Research Article

\title{
New Model of Food Supply Chain Finance Based on the Internet of Things and Blockchain
}

\author{
Yan Hong \\ School of Accounting \& Finance, Shandong Institute of Commerce and Technology, Jinan 250103, Shandong, China \\ Correspondence should be addressed to Yan Hong; 20110675@sict.edu.cn
}

Received 19 May 2021; Revised 8 June 2021; Accepted 5 July 2021; Published 30 July 2021

Academic Editor: Sang-Bing Tsai

Copyright (C) 2021 Yan Hong. This is an open access article distributed under the Creative Commons Attribution License, which permits unrestricted use, distribution, and reproduction in any medium, provided the original work is properly cited.

\begin{abstract}
The grain supply chain not only broadens the financing channels for small and medium-sized enterprises in the supply chain and strengthens the cohesion of the supply chain but also opens up new business models and sources of profit for commercial banks. This article aims to study the use of advanced information technologies such as mobile Internet, Internet of Things (IoT) transmission, BT, and other advanced information technologies to design intelligent grain depot integrated systems based on the IoT technology, in accordance with the principles of practicality and advancement, to realize the informatization of the daily management of the grain depot and provide construction experience for the informatization construction of the food industry. This article proposes a detailed summary of several models of agricultural supply chain finance from the perspective of supply chain management and analyzes the applicable conditions and basic processes of these models. It also analyzes the structure of the agricultural supply chain through typical cases, introduces the operation of supply chain finance, and evaluates and analyzes its effectiveness and problems. The experimental results in this paper show that, compared with other storage methods, this solution has obvious advantages in data query efficiency and data storage cost. Without a central server, the entire distributed system will have a certain degree of efficiency, reliability, and cost-effectiveness. When the amount of grain data reaches 100,000, 1 million, and 10 million, the system data integrity check time is 0.0263 seconds, 0.3251 seconds, and 1.5032 seconds, respectively. The program seems very useful.
\end{abstract}

\section{Introduction}

1.1. Background. Our country is facing severe food security issues. Establishing and improving the development mechanism of my country's food supply chain is an effective measure to ensure the stability and safety of domestic food. In response to changes in the domestic and international situation, food companies have begun to build a food supply chain system to promote the close coordination of business operation procedures and the use of information systems in the process of food production and processing, to achieve the goal of efficient circulation and sharing of information in the supply chain, and ultimately improve. The overall efficiency of the supply chain reduces the difficulty of tracing responsibility and government supervision. There are various problems in the traditional grain industry. Nowadays, some grain companies follow the new era of "Internet +" to create a service platform with symmetrical information between supply and demand parties, providing supply and demand service information, logistics information, price information, and so forth. It can solve the problem of the asymmetry of food supply and demand information. Due to these food information problems, coupled with the numerous links in the food supply chain, the problem of excessive costs caused by it can be correspondingly alleviated. The "Internet +" food supply chain is to break the traditional development model of the food industry and develop it into a new type of food supply chain that meets the needs of the market.

1.2. Significance. The research results will promote the specialized and unified transformation of the grain supply chain and make grain circulation more convenient and 
faster. Grain production suppliers, grain processing companies, grain distributors, and grain end consumers can learn about food market-related information in real time, improve the transparency of the food market, promote the exchange of corporate information in all links of the food supply chain, reduce the undesirable results caused by unnecessary information asymmetry, improve the stability of the food supply chain, and resolve the contradiction between food supply and demand. Related departments provided references and ideas. The expansion from the sales end to the production end will drive the formation of a market-oriented approach that combines "Internet + " with a green development of production organization, which is in line with the structural reform of the food supply side. In the new era of "Internet + ," adopt the new mode of innovative marketing of grain economy enterprises, build a grain online and offline e-commerce platform, and establish a grain network to develop the grain economy, thereby broadening grain distribution channels and promoting grain information flows quickly. The grain e-commerce platform integrates the information from both the grain producer and the grain consumer and reflects the supply and demand information of the grain market in real time, thus effectively solving the problem of grain information asymmetry.

1.3. Related Work. Mattevi and Jones' research has shown testing traceability concepts, driving factors, system characteristics, benefits and barriers, and understanding of the framework, with a focus on British SMEs operating in the food supply chain. It was also found that small and mediumsized enterprises did not regard technology as a driving force for traceability. In the field of supply chain, with the rapid development of Internet technology, many emerging technologies have been applied to the traceability system [1]. However, due to the uncertainty of the experimental process, there are still gaps in the experimental results. Tian et al. believe that the new technology of blockchain (BT) is a breakthrough innovation in decentralized information technology, and it proposes a new method. When faced with massive amounts of data in the real world, scalability has become a primary and urgent issue $[2,3]$. However, since this technology is still in its infancy, it has some inherent flaws. The purpose of Ambekar's research is to model the distribution phase of the public distribution system (PDS) and optimize the inventory strategy in this phase, so as to solve some low-efficiency problems in the system. In this study, the supply chain is modeled as a multistage supply chain composed of a warehouse, distribution center, parity store, and cardholder. The two-stage modeling method is used to model the distribution phase in PDS [4, 5]. However, there are many influencing factors in this research process, so the experimental results have certain differences.

1.4. Innovation. The innovation of this article is as follows: (1) proposing a data-sharing scheme based on BT, which comprehensively considers the security and efficiency of data sharing; (2) using the advantages of BT technology, applying BT technology to the traditional agricultural product supply chain based on the IoT technology, and designing the concept and reference frame of the agricultural product supply chain system based on BT and IoT technology; and (3) the combination of BT technology and the IoT improving the transparency and efficiency of the supply chain. This article demonstrates the application of IoT BT in the supply chain field and its advantages and disadvantages $[6,7]$.

\section{Related Algorithms of Food Supply Chain}

Through the pallet “+” technology supervision model, it is possible to realize the intelligent supervision of movable assets and the digitization of assets, successfully connect the grain assets of upstream and downstream enterprises in the grain industry supply chain with the funds of financial institutions such as banks, help enterprises in the grain supply chain solve financing problems, and enable financial institutions to quickly cut into the financial services of the food supply chain $[8,9]$.

\subsection{Service Description Matching}

Definition 3.1. Service description file $D=\left\{t_{1}, t_{2}, \ldots, t_{n}\right\}$, where $t$ is the characteristic condition of the service description and $n$ is the number of characteristic conditions $[10,11]$.

Definition 3.2. Service description file feature vector $\left\{w_{1}, w_{2}, \ldots, w_{n}\right\}$, where $w_{j}$ is the corresponding weight in the service description file $[12,13]$. The weight of feature condition $j$ in service description file $i$ can be expressed as $w_{i j}=t f_{i j} \times \log _{2}\left(N / d f_{i}\right)$, where $t f_{i j}$ is the number of feature condition $j$ in service description file $i, N$ is the total number of service description files, and $d f_{j}$ is the number of service description files containing feature condition $j$ $[14,15]$.

If the feature vector of the requested service description file is $\overline{W_{r}}=\left\{W_{r, 1}, W_{r, 2}, \ldots, W_{r, n}\right\}$, the feature vector of the service in $C_{a}$ is $\overline{W_{c}}=\left\{W_{c, 1}, W_{c, 2}, \ldots, W_{c, n}\right\}$, and $C_{a}$ is the angle between $\overline{W_{r}}$ and $\overline{W_{c}}$; the similarity is shown as follows $[16,17]$ :

$$
\operatorname{Sim}\left(\overline{W_{r}}, \overline{W_{c}}\right)=\operatorname{cosine}(\theta)=\frac{\overline{W_{r}} \cdot \overline{W_{c}}}{\left|\overline{W_{r}}\right| \times\left|\overline{W_{c}}\right|}=\frac{\sum_{i=1}^{n} W_{r, i} \times W_{c, i}}{\sqrt{\sum_{i=1}^{n}\left(W_{r, i}\right)^{2} \times\left(W_{c, i}\right)^{2}}}
$$


Among them, $W_{r, i}$ is the weight of the $i$ th characteristic condition in the description file $D_{r}$ and $W_{c, i}$ is the weight of the $i$ th characteristic condition in the description file $D_{c}$. If $\operatorname{Sim}\left(\overline{W_{r}}, \overline{W_{c}}\right)>\delta_{b}$, the service description match is satisfied, and $S_{c}$ is added to $C_{b}[18,19]$.

2.2. Dimensionless Qos Parameters. According to the different measurement methods and values of QoS parameters, it can be divided into numerical type, text type, hierarchical type, and Boolean type [20,21]. Among them, the numerical type can be divided into the precise type and interval type. It uses specific numerical values to indicate the value of QoS parameters, such as $0.5,[2,5]$; text type uses orderly and limited clauses to describe QoS parameters values, such as \{excellent, good, acceptable, poor\}; hierarchical type uses discrete value sets to describe QoS parameter values, such as $\{1,2,3,4,5\}$; and Boolean type uses only Boolean values to describe QoS parameters values, such as \{TRUE, FALSE\} $[22,23]$.

2.2.1. Standardization of Precision Parameters. From the service quality trend attribute in the introduced QoS parameter model, it can be seen that different QoS parameters have different influences on the comprehensive QoS of the service, including two relations of proportional and inverse $[24,25]$. When the QoS parameter is a proportional parameter, the standardized formula is shown as follows:

$$
V_{i j}= \begin{cases}\frac{q_{i j}-q_{j}^{\min }}{q_{j}^{\max }-q_{j}^{\min },} & q_{j}^{\max }-q_{j}^{\min } \neq 0, \\ 1, & q_{j}^{\max }-q_{j}^{\min }=0 .\end{cases}
$$

Similarly, when the QoS parameter is an inversely proportional parameter, the standardization is as follows:

$$
V_{i j}= \begin{cases}\frac{q_{j}^{\max }-q_{i j}}{q_{j}^{\max }-q_{j}^{\min },} & q_{j}^{\max }-q_{j}^{\min } \neq 0, \\ 1, & q_{j}^{\max }-q_{j}^{\min }=0 .\end{cases}
$$

2.2.2. Standardized Processing of Interval Data. Different from the uniqueness of precise data, interval data has two values: an upper limit and a lower limit. Here, a standardization method similar to that of precise data is adopted; that is, the upper and lower limits of the interval are first standardized and then the average is taken. If the QoS parameter is a proportional parameter, it is shown in the following standardized formulas:

$$
\begin{aligned}
& V_{i j}= \begin{cases}\frac{q_{i j}-q_{j}^{\min }}{\bar{q}_{j}^{\max }-\overline{q_{j}^{\min }}}, & \underline{q_{j}^{\max }}-\underline{q_{j}^{\min }} \neq 0, \\
1, & \underline{q_{j}^{\max }}-\underline{q_{j}^{\min }}=0,\end{cases} \\
& V_{i j}= \begin{cases}\overline{\overline{q_{i j}}-\overline{q_{j}^{\min }}}, \overline{q_{j}^{\max }}-\overline{q_{j}^{\min }}-\overline{q_{j}^{\min }} \neq 0, \\
1, & \overline{q_{j}^{\max }}-\overline{q_{j}^{\min }}=0,\end{cases} \\
& V_{i j}=\frac{V_{i j}+\overline{V_{i j}}}{2} .
\end{aligned}
$$

Among them, the $j$-th service quality parameter value $q_{i j}=\left[\overline{q_{i j}}, \underline{q_{i j}}\right]$ of the $i$-th service in the service set $C$ is to be selected; that is, $\overline{q_{i j}}$ and $\underline{q_{i j}}$ are the upper and lower limits of the corresponding interval and $q^{\max }$ and $q^{\min }$ are the upper and lower limits of all intervals in the jth column of matrix $Q$, respectively. The maximum value and minimum value of the lower limit: $\overline{q_{j}^{\max }}$ is the maximum value of the upper limit of the interval, $\overline{V_{i j}}$ and $V_{i j}$ are the standardized results of the upper and lower limits of the interval, and the average of the two is taken to obtain the standardized result corresponding to $V_{i j}$. Similarly, when the QoS parameter is an inversely proportional parameter, the following standardized formulas are shown $[26,27]$ :

$$
\begin{aligned}
& V_{i j}= \begin{cases}\frac{q_{j}^{\max }-q_{i j}}{\underline{q_{j}^{\max }}-\underline{q_{j}^{\min }},} & \underline{q_{j}^{\max }-\underline{q_{j}^{\min }} \neq 0,} \\
1, & \underline{q_{j}^{\max }-q_{j}^{\min }}=0,\end{cases}
\end{aligned}
$$

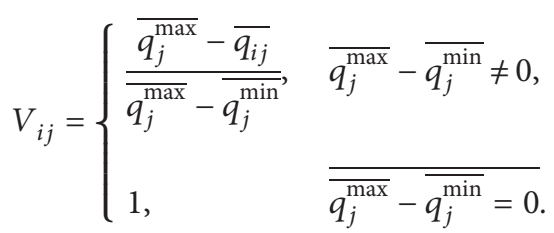

If the same QoS parameter value in the candidate service set has both an accurate value and an interval value, the accurate value is regarded as a special interval value, namely, $q_{i j}=q_{\max }=q_{\min }$, and then standardized $[28,29]$.

2.3. Coupling Mapping Lattice. The commonly used asymmetric diffusion coupled lattice model can be written as

$$
x_{n}(i+1)=(1-\varepsilon) f\left(x_{n}(i)\right)+\varepsilon\left[\alpha f\left(x_{x-1}(i)\right)+(1-\alpha) f\left(x_{n+1}(i)\right)\right] .
$$

From it, the following three typical spatiotemporal chaotic system models evolved. 
One-way coupled map lattice model:

$$
x_{n}(i+1)=(1-\varepsilon) f\left(x_{n}(i)\right)+\varepsilon f\left(x_{x-1}(i)\right) .
$$

Two-way coupled map lattice model:

$$
x_{n}(i+1)=(1-\varepsilon) f\left(x_{n}(i)\right)+\frac{\varepsilon}{2}\left[f\left(x_{x-1}(i)\right)+f\left(x_{n+1}(i)\right)\right] \text {. }
$$

Whole coupled map lattice model:

$$
x_{n}(i+1)=(1-\varepsilon) f\left(x_{n}(i)\right)+\frac{\varepsilon}{L} \sum_{j=1}^{L} f\left(x_{j}(i)\right) \text {. }
$$

In equations (5)-(8), $i$ is the discrete time coordinate, $n$ is the discrete space coordinate, $\varepsilon$ is the coupling coefficient, $L$ is the length of the system, and the nonlinear image $f\left(x_{n}(i)\right)$ reflects the local reaction process. At present, the first two models are mainly used when studying the application of spatiotemporal chaos in information encryption.

\section{Based on the Design of the Food Supply Chain Financial System}

The food supply chain has a dual meaning, that is, a narrow and broad food supply chain. The narrow meaning refers to the active construction of a supply chain centered on the logistics and information flow of food products when food products reach the end users. In a broad sense, the grain supply chain refers to the logistics and information network centered on grain logistics during the process of grain production, processing, and circulation and then to the final consumer.

\subsection{Defects of the Traditional Centralized Food Supply Chain} Financial System. Traditional supply chain financial systems mostly use centralized system architecture design. There is an absolutely trusted institution in the centralized system architecture. All users participating in the system agree with this trusted institution. The agency can solve problems in system transactions, such as preventing fraud, encrypting transaction privacy data and system user data, preventing the system from network attacks, and so on. Banks, Alipay, and so on are typical centralized system architectures. The centralized system architecture diagram is shown in Figure 1.

Although the centralized system architecture can solve fraudulent behaviors in the transaction process to a certain extent and protect the privacy data of system users, the centralized system architecture still has the following problems: (1) a reliable institution in the central system can read the data of any user in the system, because there is no effective way to supervise the central institution, and the central institution abuses the data. (2) In the case of the central system, there are gaps in the system design of the trust center, and system privacy data may be lost, transaction data may be compromised, or the central organization may resell user data. You can violate the system at will for the benefit of organizing your data.
3.2. Architecture Design of Supply Chain Financial System. According to the overall architecture design, the system is divided into the basic financial platform and business service platform. The core financial platform mainly includes the BT level and financial service level. The BT layer is based on the hyperledger fabric project and creates basic level BT technology for data transmission services such as data security storage and data synchronization. The service interface is the service level provided to the business service platform, which is used to quickly access the BT network layer for data interaction. The operation and maintenance platform provides BT network level and financial services, required operation, and maintenance functions. The business service platform mainly includes the back end of supply chain finance and the front end of supply chain finance. Its main function is to act as a platform level to transfer various business processes to the financial sector, and various functions can be added, specific companies to meet different operational needs. Figure 2 shows the architecture of the whole system.

3.3. Module Docking. The BT network is mainly connected to the service interface module and connected with the service interface to provide BT services at the back end of supply chain finance. It includes the BT management module, BT service module, and distributed network service module. The structure of the BT network and interface services is shown in Figure 3.

As can be seen from Figure 3, member management includes member registration, member comments, and member authentication. BT services perform related management consents and $\mathrm{P} 2 \mathrm{P}$ communication management functions. The code chain service performs chain code container and chain code development operations. Distributed workbooks store data in business processes. The service interface includes four functional modules: fabric SDK, privilege management, certificate management, and plan control. They provide supply chain finance with interfaces for packet and call delivery, certificates, and permissions. Among them, scheduling control is to enter the financial back end call of the supply chain, call certificate management, user identity and privilege management, and the result-based SDK call to realize the requested function. Authority management is responsible for managing the role and operation authority of the supply chain system. Certificate management platform client functions are associated with certificates.

\section{Food Supply Chain Driven by the IoT and BT}

The purpose of the grain warehousing process driven by IoT technology is to accurately collect the information of the grain in the warehouse and to put the grain in the warehouse and place it in the appropriate storage area. Using RFID technology in the IoT technology can improve the accuracy of information collection and reduce time and labor costs.

4.1. Inspection. Grain classification in the grain inspection process is an important part of the grain storage process and is directly related to the quality of grain storage. The biggest 


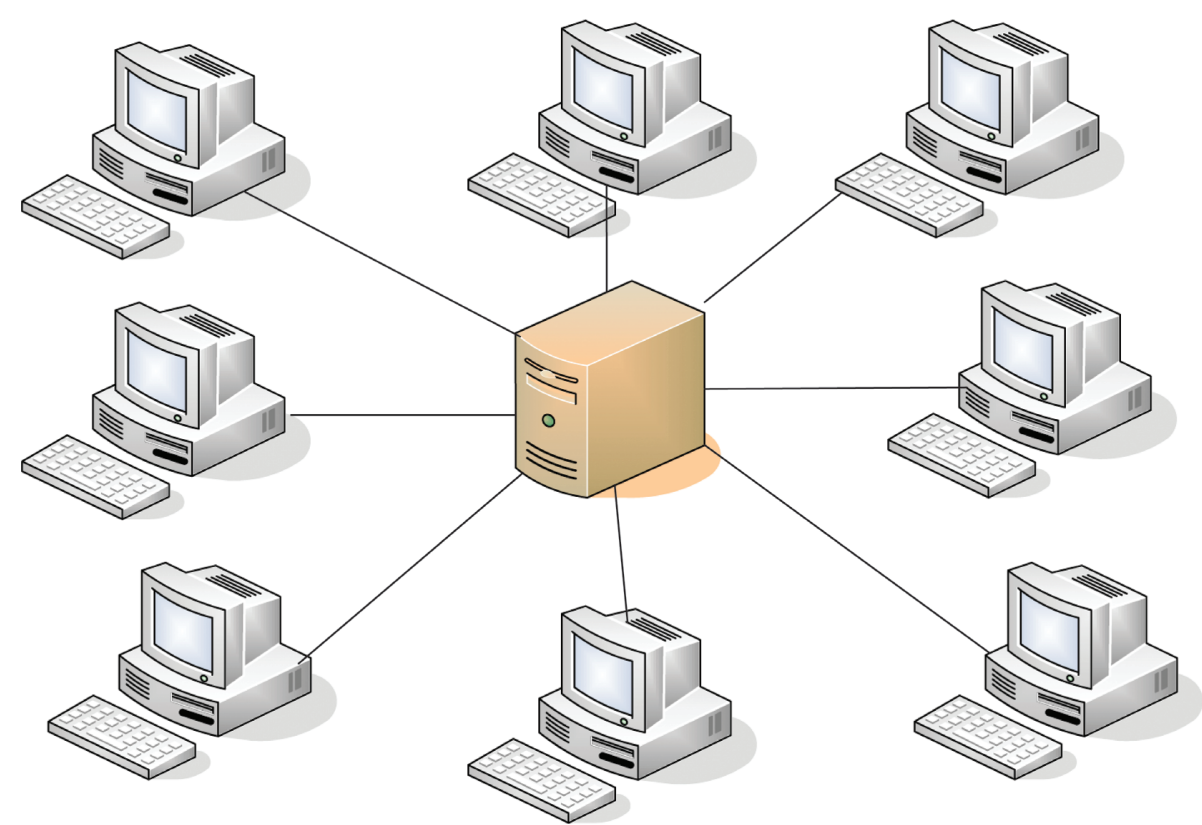

Figure 1: Centralized system architecture.

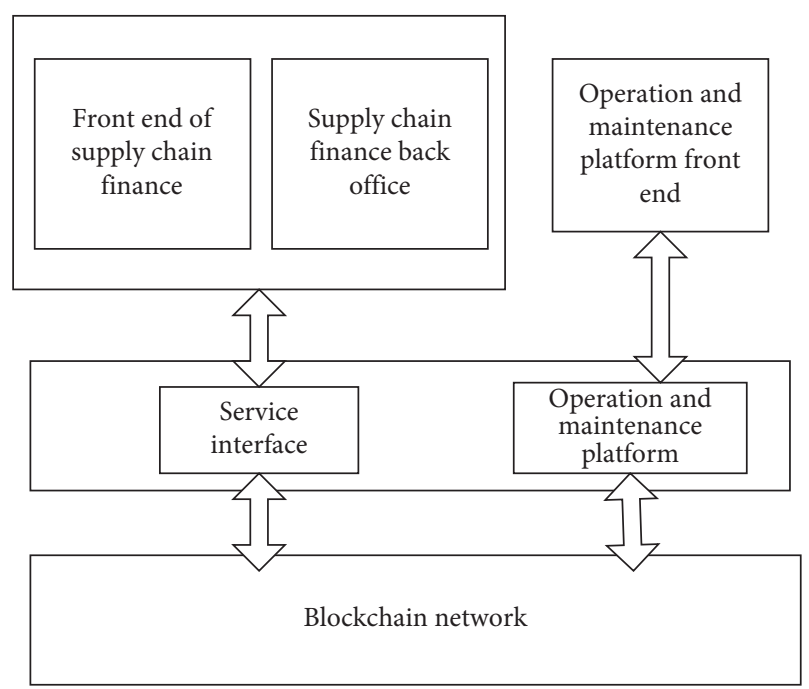

FIGURE 2: Overall system architecture.

problem with the barn is that it is not strictly monitored during the grain inspection process. Therefore, it is very important to conduct real-time inspections during the storage inspection stage to inspect grains. At present, rice, wheat, and corn are the most widely grown grains in our country. Therefore, rice, wheat, and corn are the most stored grains in granaries. Therefore, in this case, the inspection of rice is taken as an example to illustrate the inspection of grain.

As shown in Tables 1 and 2, take the rice warehousing as an example. In the grain inspection, the inspector randomly samples the grain in the grain truck and uses related instruments to determine the roughness rate and the whole rice rate of the sampled rice and the pollutants according to the standard. The rice grains are graded and then operated in

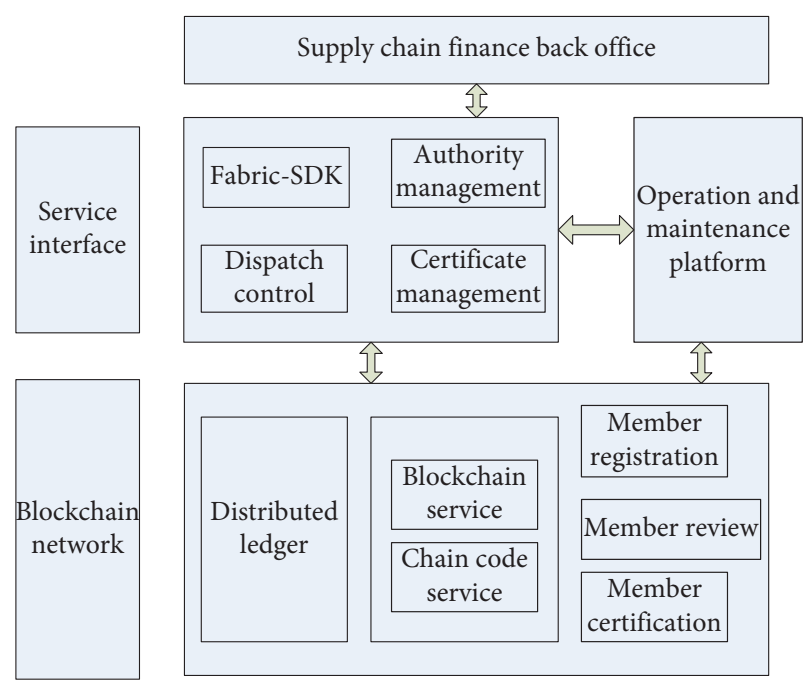

FIgURE 3: BT network and interface service structure.

accordance with the operating specifications of the granary. Those that meet the storage requirements are put into the warehouse, and those that do not meet the requirements are returned. At the same time, the whole process of video image monitoring needs to be carried out during the grain inspection stage to ensure that there is no interference from other factors in the incoming grain inspection, and at the same time, when the result of the grain inspection fails, the problem can be quickly found.

4.2. System Operating Efficiency. Table 3 shows the traceability query time for 100,000 batches of grain data. Since the supply chain currently has 5 levels, the traversal depth is 5 . It can be seen that, for enough data, the query time is within 10 seconds. 
TABLE 1: Rice quality indicators.

\begin{tabular}{|c|c|c|c|c|c|c|}
\hline Grade & $\begin{array}{c}\text { Roughness ratio } \\
(\%)\end{array}$ & $\begin{array}{c}\text { Head rice rate } \\
(\%)\end{array}$ & $\begin{array}{c}\text { Impurity content } \\
(\%)\end{array}$ & $\begin{array}{c}\text { Moisture content } \\
(\%)\end{array}$ & $\begin{array}{l}\text { Yellow-grain rice } \\
\text { content (\%) }\end{array}$ & $\begin{array}{c}\text { Brown-content outside } \\
\text { grain }(\%)\end{array}$ \\
\hline 1 & $\geq 79.0$ & $\geq 50.0$ & & & & \\
\hline 2 & $\geq 77.0$ & $\geq 47.0$ & & & & \\
\hline 3 & $\geq 75.0$ & $\geq 44.0$ & $\leq 1.0$ & $\leq 13.5$ & $\leq 1.0$ & $\leq 2.0$ \\
\hline 4 & $\geq 73.0$ & $\geq 41.0$ & & & & \\
\hline 5 & $\geq 71.0$ & $\geq 38.0$ & & & & \\
\hline Out of class & $<71.0$ & - & & & & \\
\hline
\end{tabular}

TABle 2: Pollutant limit index.

\begin{tabular}{lcc}
\hline & Project & \\
Lead content $(\mathrm{mg} / \mathrm{kg})$ & $\leq$ & Index \\
Cadmium content $(\mathrm{mg} / \mathrm{kg})$ & Corn, wheat, and their products & 0.2 \\
& Rice, rice $\leq$ & 0.1 \\
Mercury content $(\mathrm{mg} / \mathrm{kg})$ & $\leq$ & 0.2 \\
Arsenic content $(\mathrm{mg} / \mathrm{kg})$ & Corn, wheat, and their products & 0.02 \\
Tin content $(\mathrm{mg} / \mathrm{kg})$ & $\leq$ & 0.5 \\
Chromium content $(\mathrm{mg} / \mathrm{kg})$ & $\leq$ & 250 \\
Benzopyrene content $(\mu \mathrm{g} / \mathrm{kg})$ & $\leq$ & 1.0 \\
\hline
\end{tabular}

TABLE 3: Data query time statistics.

\begin{tabular}{lccc}
\hline Quantity & Data integrity check $(\mathrm{s})$ & Graph database query $(\mathrm{s})$ & Smart contract extraction \\
\hline 100000 & 0.0263 & 2.41 & Gas \\
1000000 & 0.3251 & 2.65 & Gas \\
10000000 & 1.5032 & 3.25 & Gas \\
\hline
\end{tabular}

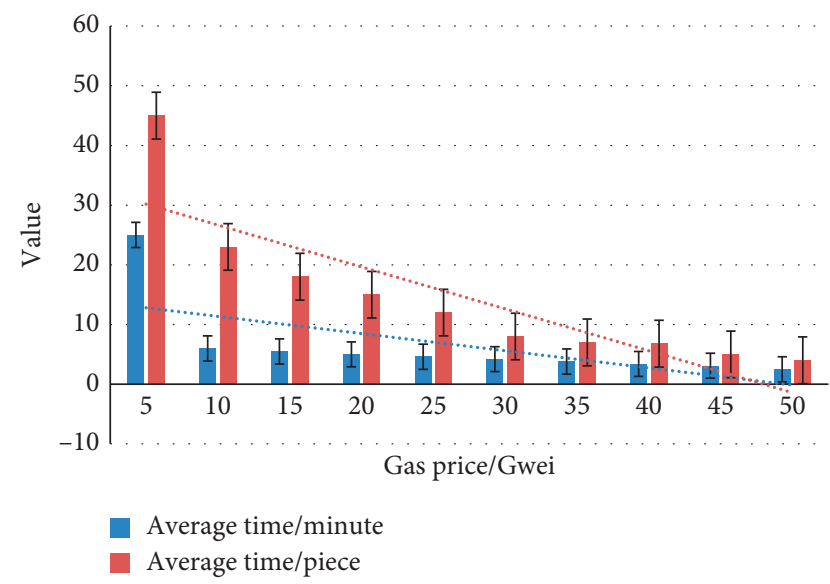

FIGURE 4: Relationship between gas price and transaction effective time.

The storage and retrieval duration of smart contract queries depends on the gas value of the transaction. Therefore, the higher the gas value, the faster the creation of transactions on the Ethereum blockchain, but the higher the corresponding cost. The following table shows the relationship between gas consumption and production time. You will see that the higher the gas usage on the horizontal axis, the shorter the actual average transaction time. The cost of using the public chain to store data in the transaction segment price is only $\$ 0.000005$, while the cost of the public chain to store all traceable initial information is $\$ 1.76$.

The conclusion drawn from Figure 4 is that, using GrainTrail's decentralized storage solution, Neo4j for auxiliary storage can minimize the storage cost of the BT, while using the BT as a necessary tool to ensure that data cannot be tampered with and, at the same time, increase the credibility of the system. Because the Neo4j graph database has outstanding performance in traversal query, it can support users' complex query functions.

\section{Conclusions}

In the rural grain financial market, the competition of financial institutions presents the characteristics of diversification and diversity. Food financial institutions can fully use their role in the food production supply chain and market value chain to establish a network serving food production, thereby establishing an important position in food. Some financial institutions are exploring and summarizing the supply chain financing models suitable for the development of local grain industrialization and promoting them, which has promoted the expansion of the grain supply chain financing business scale. Supply chain finance has many customers, but the focus is on the core enterprise, which is the leader of the supply chain organization. In a sense, choosing a supply chain is choosing a core enterprise, 
and seizing the core enterprise is the key. Grain financial institutions are familiar with the grain market and have a large amount of valuable information about core corporate customers. Grain financial institutions should combine their own advantages in the supply chain and customer structure, step by step, and promote the grain supply chain finance of the factory in stages. Financial institutions can use online platforms to carry out online grain supply chain financing services. Loan application, review, loan issuance, and so on can all be done online. Taking innovation as a breakthrough, expand the supply chain financial service model. Financial institutions should actively innovate and explore diversified supply chain financing service models and introduce equity in accordance with the development stage of the supply chain and the different financial needs of agricultural planting, animal husbandry and fishery breeding, crop processing, agricultural raw material supply, and agricultural product sales. Modern financial service methods such as custody and trust financing promote the rapid and healthy development of the supply chain.

\section{Data Availability}

The data that support the findings of this study are available from the corresponding author upon reasonable request.

\section{Conflicts of Interest}

The author declares no potential conflicts of interest with respect to the research, authorship, and/or publication of this article.

\section{References}

[1] M. Mattevi and J. A. Jones, "Food supply chain: are UK SMEs aware of concept, drivers, benefits and barriers, and frameworks of traceability?" British Food Journal, vol. 118, no. 5, pp. 1107-1128, 2016.

[2] F. Tian, "A supply chain traceability system for food safety based on HACCP, BT \& IoT," in Proceedings of the International Conference on Service Systems \& Service Management, pp. 585-598, Dalian, China, June 2017.

[3] Y. Sun, H. Song, A. J. Jara, and R. Bie, "Internet of things and big data analytics for smart and connected communities," IEEE Access, vol. 4, pp. 766-773, 2016.

[4] J. Chi, Y. Li, J. Huang et al., "A secure and efficient data sharing scheme based on blockchain in industrial internet of things," Journal of Network and Computer Applications, vol. 167, p. 102710, 2020.

[5] Z. Yushu, H. Qi, C. Guo, Z. Xinpeng, and X. Yong, "A lowoverhead, confidentiality-assured, and authenticated data acquisition framework for IoT," IEEE Transactions on Industrial Informatics, vol. 16, no. 12, pp. 7566-7578, 2020.

[6] X. Lyu, W. Ni, H. Tian et al., "Optimal schedule of mobile edge computing for internet of things using partial information," IEEE Journal on Selected Areas in Communications, vol. 35, no. 11, pp. 2606-2615, 2017.

[7] M. M. Rathore, A. Ahmad, A. Paul, and S. Rho, "Urban planning and building smart cities based on the internet of things using big data analytics," Computer Networks, vol. 101, pp. 63-80, 2016.
[8] Y. Zhang, H. Huang, L.-X. Yang, Y. Xiang, and M. Li, "Serious challenges and potential solutions for the industrial internet of things with edge intelligence," IEEE Network, vol. 33, no. 5, pp. 41-45, 2019.

[9] Z. Lv, Y. Han, A. K. Singh et al., "Trustworthiness in industrial IoT systems based on artificial intelligence," IEEE Transactions on Industrial Informatics, vol. 17, no. 2, pp. 1496-1504, 2021.

[10] M. Ma, D. He, N. Kumar et al., "Certificateless searchable public key encryption scheme for industrial IoT," IEEE Transactions on Industrial Informatics, vol. 14, no. 99, pp. 759-767, 2018.

[11] V. Scuotto, A. Ferraris, and S. Bresciani, "Internet of things: applications and challenges in smart cities: a case study of IBM smart city projects," Business Process Management Journal, vol. 22, no. 2, pp. 357-367, 2016.

[12] S. R. Chandra and Y. Wang, "Cloud things construction-the integration of IoT and cloud computing," Future Generation Computer Systems, vol. 56, pp. 684-700, 2016.

[13] A. Augustin, J. Yi, T. Clausen, and W. Townsley, "A study of LoRa: long range \& low power networks for the internet of things," Sensors, vol. 16, no. 9, p. 1466, 2016.

[14] V. Pande, C. Marlecha, and S. Kayte, "A review-fog computing and its role in the IoT," International Journal of Engineering Research and Applications, vol. 6, no. 10, pp. 2248-96227, 2016.

[15] A. V. Dastjerdi and R. Buyya, "Fog computing: helping the internet of things realize its potential," Computer, vol. 49, no. 8, pp. 112-116, 2016.

[16] C. Perera, C. H. Liu, and S. Jayawardena, "The emerging internet of things marketplace from an industrial perspective: a survey," IEEE Transactions on Emerging Topics in Computing, vol. 3, no. 4, pp. 585-598, 2015.

[17] A. Kamilaris and A. Pitsillides, "Mobile phone computing and the internet of things: a survey," IEEE Internet of Things Journal, vol. 3, no. 6, pp. 885-898, 2017.

[18] J. C. Balda, A. Mantooth, R. Blum, and P. Tenti, "Cybersecurity and power electronics: addressing the security vulnerabilities of the internet of things," IEEE Power Electronics Magazine, vol. 4, no. 4, pp. 37-43, 2017.

[19] N. Abuzainab, W. Saad, C. S. Hong, and H. V. Poor, "Cognitive hierarchy theory for distributed resource allocation in the internet of things," IEEE Transactions on Wireless Communications, vol. 16, no. 12, pp. 7687-7702, 2017.

[20] H. Schebesta, T. Verdonk, P. P. Kai et al., "Unfair trading practices in the food supply chain: regulating right?" European Journal of Risk Regulation, vol. 9, no. 4, pp. 1-11, 2019.

[21] M. Shacklett, "Track and trace in the food supply chain," Food Logistics, vol. 26, no. 204, pp. 26-31, 2019.

[22] P. Rakesh, A. Sunil, and P. Saurabh, "Development of novel strategies for designing sustainable Indian agri-fresh food supply chain," Sādhanā, vol. 43, no. 10, p. 167, 2018.

[23] G. Ji, L. Hu, and K. H. Tan, "A study on decision-making of food supply chain based on big data," Journal of Systems Science and Systems Engineering, vol. 26, no. 2, pp. 183-198, 2017.

[24] M. Mattevi and J. A. Jones, "Traceability in the food supply chain: awareness and attitudes of UK small and medium-sized enterprises," Food Control, vol. 64, pp. 120-127, 2016.

[25] D. Milicevic, I. Nastasijevic, and Z. Petrovic, "Mycotoxin in the food supply chain-implications for public health program," Journal of Environmental Science \& Health Part C Environmental Carcinogenesis Reviews, vol. 34, no. 4, pp. 293-319, 2016. 
[26] H. Honar Pajooh, M. Rashid, F. Alam, and S. Demidenko, "Multi-layer blockchain-based security architecture for internet of things," Sensors, vol. 21, no. 3, pp. 772-773, 2021.

[27] S.-B. Tsai, R. Saito, Y.-C. Lin et al., "Discussing measurement criteria and competitive strategies of green suppliers from a green law perspective," Proceedings of the Institution of $\mathrm{Me}$ chanical Engineers, Part B: Journal of Engineering Manufacture, vol. 229, no. 1, pp. 135-145, 2015.

[28] S. Hameed, S. A. Shah, Q. S. Saeed et al., "A scalable key and trust management solution for IoT sensors using SDN and blockchain technology," IEEE Sensors Journal, vol. 21, no. 6, pp. 8716-8733, 2021.

[29] D. K. Kamel, "Wireless IoT with blockchain-enabled technology amidst attacks," IRO Journal on Sustainable Wireless Systems, vol. 2, no. 3, pp. 133-137, 2021. 